\title{
Emotion, Memory, Meaning, Directions: A Response to Kirsten Marie Hartvigsen and Thomas J. Kraus
}

\author{
Evert van Emde Boas \\ Aarhus University, Aarhus, Denmark \\ evert.vanemdeboas@cas.au.dk
}

\begin{abstract}
This response article reviews the contributions of Kirsten Marie Hartvigsen and Thomas Kraus to this special issue, and uses them as the basis for a discussion of some theoretical and methodological issues relevant to cognitive narratology and cognitive literary studies more broadly. Without offering substantial answers itself, the response poses questions concerning (i) the compatibility of different scientific frameworks used in cognitive models of characterization, particularly in the light of currently dominant '4EA' models of cognition (there is a particular focus on the relationship between affective and (other) cognitive aspects of reader response, and on the role of memory); and (ii) the adaptability of cognitive models to dealing with "synthetic" and "thematic" (as opposed to "mimetic") aspects of literary character. A brief conclusion argues for two-way traffic between the cognitive sciences and literary criticism.
\end{abstract}

\section{Keywords}

cognitive narratology - cognitive literary studies - 4EA cognition - affective literary response - memory - character ontology

\section{Introduction}

It may be suitable to start this response with a brief word about my own angle of approach. I come to these papers as a classicist with an interest in cognitive approaches, particularly as they pertain to the study of characterization in (archaic and classical) ancient Greek literature. I thus share with the authors of these two papers, as well as those of the others in this special issue, a broad 
methodological interest, and even some specific experience in trying to make sense of the characters we find in literature written in Ancient Greek. ${ }^{1}$ That said, my expertise falls squarely outside of the field of New Testament studies (it is a regrettable truism that our academic disciplines often operate independently from each other). What I can hope to offer at best, then, is something of a "view from classics," however partial. My views on characterization are influenced by the nature of the debate surrounding that topic as it has been held, through sometimes fierce fits and starts, in my own discipline, ${ }^{2}$ and my ideas about the value of (different directions in) cognitive literary studies are equally informed by the particular ways in which that enterprise has taken root, quite recently, within classics. ${ }^{3}$

The two papers to which I have been invited to respond complement each other wonderfully well. Their introductory sections, when taken together, offer

1 K. De Temmerman and E. van Emde Boas (eds.), Characterization in Ancient Greek Literature (Leiden: Brill, 2018); E. van Emde Boas, Language and Character in Euripides' Electra (Oxford: Oxford University Press, 2017); idem, "The Linguistic Characterization of Oedipus in OT: A Pragmatics-Based Approach to 'Mind Style," in G. Martin, F. Iuresca, S. Hof, and G. Sorrentino (eds.), Pragmatic Approaches to Drama: Studies in Communication on the Ancient Stage (Leiden: Brill, 2021), 96-120; idem, "Individuals or Types? Ancient Criticism and Modern Psychology on Characterization in Greek Tragedy," in L. Huitink, I. Sluiter (eds.), Doing the Psychology of the Ancient World (Leiden: Brill, forthcoming); idem, "Mindreading, Character, and Realism: The Case of Medea" in F. Budelmann, I. Sluiter (eds.), Minds on Stage: Cognitive Approaches to Greek Tragedy (Oxford: Oxford University Press, Forthcoming).

2 Some relevant survey discussions are C.B.R. Pelling, "Conclusion," in C.B.R. Pelling (ed.), Characterization and Individuality in Greek Literature (Oxford: Oxford University Press, 1990), 245-262. (with the rest of the volume); K. De Temmerman, Crafting Characters: Heroes and Heroines in the Ancient Greek Novel (Oxford: Oxford University Press, 2014), 1-45; De Temmerman and van Emde Boas (eds.), Characterization, 1-23.

3 Relevant examples are the following edited volumes: J. Lauwers, J. Opsomer, and H. Schwall (eds.), Psychology and the Classics: A Dialogue of Disciplines (Berlin: De Gruyter, 2018); M. Anderson, D.L. Cairns, and M. Sprevak (eds.), Distributed Cognition in Classical Antiquity (Edinburgh: Edinburgh University Press, 2019); P. Meineck, W.M. Short, and J. Devereaux (eds.), The Routledge Handbook of Classics and Cognitive Theory (London: Routledge, 2019); J. Grethlein, L. Huitink, and A. Tagliabue (eds.), Experience, Narrative, and Criticism in Ancient Greece: Under the Spell of Stories (Oxford: Oxford University Press, 2020); F. Budelmann and I. Sluiter (eds.), Minds on Stage: Cognitive Approaches to Greek Tragedy (Oxford: Oxford University Press, Forthcoming). Each of these has introductions that survey (parts of) the field: particularly useful are F. Budelmann, "Introduction," in Budelmann and Sluiter, Minds, and D. Cairns, "Introduction: Distributed Cognition and the Classics," in Anderson, Cairns and Sprevak, Distributed Cognition, 18-36. I have found Felix Budelmann's introduction extremely helpful in crafting this response, and am grateful to Budelmann for allowing me to read it in advance. See also the website maintained by Felix Budelmann and Katharine Earnshaw at https://cognitiveclassics.blogs.sas.ac.uk/, including an annotated bibliography. 
a rich overview of how listeners and readers (I will below use "reader" by way of shorthand) can be thought to interpret characters in biblical literature, even if the two articles have appropriately different emphases. While Kirsten Hartvigsen's integrative model, based on a broad range of frameworks deriving from cognitive psychology, social psychology (attribution), discourse comprehension studies, cognitive linguistics, and affect studies, offers something of a roadmap to a potential understanding of the processes underpinning readers' formation of character models (and their broader responses to characters), Thomas Kraus's list of eleven "character features" focuses more on the diverse content of those models. Both are important: together they put both the "cognition" and the "narrative" in "cognitive narratology."

The papers really come into their own when we get to the eating of the pudding - that is, to the actual application of the authors' methodological frameworks to texts. Two shared aspects make Hartvigsen's reading of Luke 1:5-2:52 and Kraus's of the Acts of Peter particularly convincing and methodologically relevant, to my mind. First, both operate in a strictly linear fashion. By going through their texts from left to right and tracing relevant character cues step by step, both authors demonstrate the importance of seeing character interpretation as a dynamic process, in which readers constantly update, adjust, confirm, or sometimes fundamentally alter their constructed models of individual characters. This, of course, is a fundamental aspect of precisely the discourse processing model that, thanks to the work of Culpeper, Schneider, Jannidis, and others, ${ }^{4}$ has become so influential in studies of literary character, and that sits at the heart of both Hartvigsen's and Kraus's approach. (It also, albeit in a different way, fits in nicely with blending theory.)

Secondly, both authors are, often explicitly, sensitive to the fact that individual readers' character constructions may differ, and that what each reader

4 E.g. J. Culpeper, Language and Characterisation: People in Plays and Other Texts (Harlow: Longman, 2001); idem, "A Cognitive Stylistic Approach to Characterisation', in E. Semino, J. Culpeper (eds.), Cognitive Stylistics: Language and Cognition in Text Analysis (Amsterdam: Benjamins, 2002), 251-278; idem, "Reflections on a Cognitive Stylistic Approach to Characterisation," in J. Vandaele, G. Brône (eds.), Cognitive Poetics: Goals, Gains, and Gaps (Berlin: De Gruyter, 2009): 125-159; J. Eder, F. Jannidis, and R. Schneider, "Characters in Fictional Worlds: An Introduction," in J. Eder, F. Jannidis, and R. Schneider (eds.), Characters in Fictional Worlds (Berlin: De Gruyter, 2010), 3-65; F. Jannidis, Figur und Person: Beitrag zu einer historischen Narratologie (Berlin: De Gruyter, 2004); idem, "Character," in H. Peter, J. Pier, W. Schmid, and J. Schönert (eds.), The Living Handbook of Narratology (Hamburg: Hamburg University Press), https://www.lhn.uni-hamburg.de/node/41.html; R. Schneider, Grundriß zur kognitiven Theorie der Figurenrezeption am Beispiel des viktorianischen Romans (Tübingen: Stauffenburg, 2000); idem, "Toward a Cognitive Theory of Literary Character: The Dynamics of Mental-Model Construction," Style 25 (2001): 607-40. 
brings to the table in terms of knowledge, socio-cultural background, and so forth, is crucial to how they make sense of literary characters. All this is not quite news, perhaps, but still it is a crucial consideration given the authors' insistence on a theoretical shift towards the "contributions of readers and listeners to the construction of the narrative world."5 Importantly, the extent to which such considerations are carried through to the level of the individual reader offers a useful counterbalance to one side effect of the (understandable) desire among scholars of antiquity (or any historical period) to avoid naive transhistorical generalization. In classics, at least, a focus on cultural-historical context as the key to reconstructing "original" responses to works of literature has sometimes obscured the fact that such responses may have differed as much between one ancient reader and the next as they would between an idealized first- and a twenty-first-century reader. At any rate, the theoretical awareness that individual responses may differ is seldom as carefully worked out in practice as it is in our two papers: Hartvigsen's careful analysis of how "different audience members will regard [Mary's visit to Elizabeth at Luke 1:39-40] as an indication of different traits, preferences or goals." ${ }^{6}$ or Kraus's stipulation that Acti Petri 40.6-7 will remind "a reader who has enjoyed some theological training" of certain other biblical passages, but that such "background knowledge may not be necessary for understanding the critical tone underlying the narrative,"7 can serve as useful reminders that what readers make of characters is always contingent, and indeed contingent to the level of the individual. ${ }^{8}$

All in all, I found both Hartvigsen's readings of the characters in the early chapters of Luke and Kraus's account of the figure of Marcellus in the Acts of Peter highly convincing, and I am largely sympathetic to their approaches. What remains, then, is a set of theoretical and methodological questions. Like the papers themselves, some of these focus more on the cognitive processes

5 K.M. Hartvigsen, "How Audience Members Envision New Testament Characters: Mental Character Models, Blending, and the Reception of Luke 1:5-2:52," p. $55^{6 .}$

6 K.M. Hartvigsen, "Audience," p. 574.

7 T.J. Kraus, "Dramatis personae in the Acts of Peter: Character Identification and the Conveyance of Ethical Values," p. 611.

8 Individual differences are, of course, the bread and butter of some of the scientific disciplines with which the cognitive humanities interact, particularly social psychology (notice such journal titles as the Journal of Individual Differences and Personality and Individual Difference). On the whole, though, they have not been as central within cognitive literary studies as one might expect, with the exception of some empirical attempts, e.g. J.M. Thompson, B. Teasdale, S. Duncan, E. van Emde Boas, F. Budelmann, L. Maguire, and R.I.M. Dunbar, "Individual Differences in Transportation Into Narrative Drama," Review of General Psychology 22 (2018): 210-219. 
underpinning character interpretations, others more on the interpretations themselves. In the remainder of my response I will touch on the former (the processes) first, before concluding with some thoughts about meaning. My thoughts are all meant to be exploratory and tentative, and if I answer very few, if any, of my own questions, I can ask only for indulgence.

\section{Theories and Science, Emotion, Memory}

The list of (sub-)disciplines I mentioned above as underpinning Hartvigsen's impressive methodological apparatus-from attribution theory to blending-brings with it questions of theoretical compatibility and of truth claims. The cognitively inflected study of characterization (like all cognitive humanities, really) has from the outset been something of a grab bag: ideas from a wide range of disciplines, each with their own vast secondary literature and often with many subfields and schools of thought, are brought to bear, not always with a full accounting of the extent to which these disciplines truly mix and match. On the one hand such eclecticism is, I think, necessary-indeed I explicitly argue for it myself elsewhere. ${ }^{9}$ On the other hand, in adopting the ideas and instruments of "harder" domains of scientific enquiry, we as literary scholars should, I feel, be clear-eyed about how such domains fit together, if at all.

One relevant example here is the combination in Hartvigsen's chapter (found, to be fair to her, also in numerous other works) of Fauconnier and Turner's conceptual integration theory ('blending') with a discourse processing model based on the work of e.g. Kitsch, van Dijk, and Zwaan (via, among others, Culpeper and Schneider). It is not immediately clear, to me at least, ${ }^{10}$ precisely how we should conceptualize the relationship between these models, which both deal with how we integrate new information. ${ }^{11}$ Are they competing

9 Van Emde Boas, "Mindreading."

10 Ralf Schneider, in his response in this volume (R. Schneider, "Potential and Actual CognitiveEmotional Engagement with Characters: A Response to Michael Whitenton and Bonnie Howe \& Eve Sweetser," p. 538), usefully argues that the combination of blending with other models offers the "the potential for 'zooming' from broad levels of observation ... down to the micro-linguistic level of lexical units that trigger frames." An earlier brief assessment of the value of blending theory vis-à-vis discourse processing, specifically with a view to characterization, is Culpeper, "Reflections," 23-24.

11 I observe that both models are also often visually represented with similar graphs (a central box to which arrows run from (at least) two other boxes): compare e.g. Culpeper, Language, 35 with G. Fauconnier and M. Turner, The Way We Think: Conceptual Blending and the Mind's Hidden Complexities (New York: Basic Books, 2002), 62. 
alternatives portraying, in the end, the same thing(s)? Complementary models pertaining to different orders or realms of cognition? Does blending theory serve to explain the mechanisms behind the 'piecemeal integration' of the discourse comprehension model? To complicate matters further: while a fairly extensive empirical research programme has been developed in support of one of these models (the discourse processing one), even with experimental applications to literature, ${ }^{12}$ very little parallel empirical work has been done on blending, not least because it has proven incredibly difficult even to begin designing the relevant experiments. ${ }^{13}$ Does this experimental gap say something about the truth status, or value to literary studies, of one theory relative to the other? (Simple answers are, to my mind, to be avoided here: even when there is empirical data, its interpretation is often extremely difficult.) At any rate, how one answers these questions and others like them has considerable bearing on what we can make of a methodological apparatus like Hartvigsen's: is it a series of helpful ideas with no greater or lesser authority than any other model of literary reception, or is it an approximation, based somehow on scientific "fact," of what readers "actually" do when making sense of literary characters?

For a further potential issue of compatibility I may, perhaps, examine a brief passage from Hartvigsen's chapter in greater detail. The angel Gabriel appears to Zechariah (Luke 1:11-12):

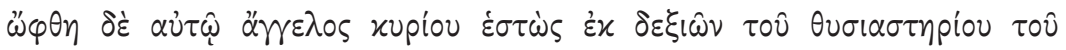

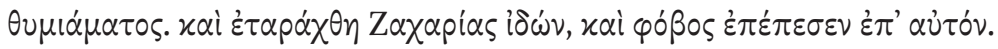

Then there appeared to him an angel of the Lord, standing at the right side of the altar of incense. When Zechariah saw him, he was terrified; and fear overwhelmed him. ${ }^{14}$

12 For overviews cf. e.g. J.R. Sparks and D. N. Rapp, "Discourse Processing: Examining Our Everyday Language Experiences," WIREs Cognitive Science 1 (2010): 371-381 (with numerous further references), or, with a greater focus on embodiment, R.A. Zwaan, "Situation Models, Mental Simulations, and Abstract Concepts in Discourse Comprehension," Psychonomic Bulletin \& Review 23 (2016): 1028-1034. Both include references to empirical studies of literary comprehension (including film). On empirical literary studies see also Schneider's response in this volume.

13 M. Turner, "Challenges to Blending Theory" (2013), https://markturner.org/Challenges ToBlendingTheory.html, under "Challenge (4)."

14 Text and translation (New Revised Standard Version) of Luke here and below: Nestle-Aland (28th edn). 
Hartvigsen comments insightfully:15

Audience members who have inferred that the angel's appearance was associated with fire, as was often the case, may regard Zechariah's fear as a result of the specific context. Audience members who are familiar with other traditions about divine intervention, will interpret Zechariah's behavior against the backdrop of genre schemata (i.e., as a common response to divine intervention in this type of literature). In both cases, they will not necessarily add the trait "fearfulness" to their mental character models of Zechariah. If audience members simulate the event from the perspective of Zechariah, they will vicariously experience the proper response to divine intervention through an angelic messenger.

This all strikes me (for what it is worth) as entirely on the money. But one may wonder how these supposed audience reactions relate to each other. Are "both cases" mutually exclusive? (And if so, is that intrinsic to the model?) More pertinently, how does the vicarious experience of a "proper response to divine intervention"- by this Hartvigsen means, I believe, an emotional experience, viz. one of fear-combine with the apparently more affect-neutral exercise in mental modelling, including the non-attribution of fearfulness to Zechariah? Do these processes happen simultaneously? Consecutively? One as the result of the other? Such questions may seem like needless pedantry; behind them, however, sit fundamental questions about the relationship between "cognitive" and "affective" responses to literature, and indeed about the nature of cognition.

It is notable, in this regard, that the happy inclusion of the emotions under "cognitive" approaches is itself a relatively recent development, one that actually postdates some of the original formulations of the relevant discourse processing models used by Culpeper, Schneider, and others (although as Schneider demonstrates in this volume, these scholars themselves have not sat still in the meantime). Those earlier models of discourse comprehension derive from a period in which views of cognition were primarily based on computational models of the mind, and in which cognition in fact stood in something like opposition to affect. More recently, dominant trends in the cognitive sciences (dominant at least in how extensively they are being applied to literature), have self-consciously positioned themselves against "first-generation" computational models. In the "second generation" cognition is now all about

15 K.M. Hartvigsen, “Audience," p. 567. 
the " $4 \mathrm{ES}$ " or even " $4 \mathrm{EA}^{\text {": }: 16}$ it is embodied and enactive (i.e. based on and constituted by our physical interactions with our environment; Cartesian mind-body dualism is the typical target for scorn here), embedded (in its various contexts), extended (e.g. to prosthetic devices; our shopping list is part of our cognitive engagement with the supermarket), and, indeed, affective (intrinsically bound up with our emotions).

If I were to attempt to craft a $4 \mathrm{EA}$-inspired reading of the same moment in Luke, the emerging view of how a reader might engage with Zechariah's character in this moment would have some different emphases. Such a reading would make much of the fact that Zechariah's reaction to Gabriel is based on visual perception $(\ddot{\omega} \varphi \theta \eta \ldots . i \delta \dot{\omega} \omega)$, of the fact that it is marked by an emotional reaction whose conceptualization has a strongly embodied character

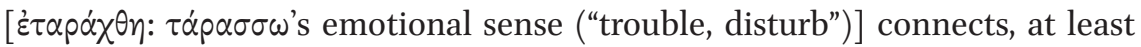
originally, to a physical one ("stir up, disturb"), and of the embodied metaphor of fear "falling onto" Zechariah ( $\dot{\varepsilon} \pi \varepsilon \dot{\varepsilon} \pi \varepsilon \sigma \varepsilon \nu)$. My reading would, perhaps, portray the scene as a neatly encapsulated "emotion event" (a term from Hogan's 'affective narratology'), ${ }^{17}$ with its emotion-provoking incident (the sudden appearance of the angel) and its emotional and expressive outcome (Zechariah's physical disturbance). I could then, finally, perhaps attempt to link all these aspects to the reader's response, arguing that the reader is invited by the rich language of perception, physical movement, and affect, to experience his/ her own embodied and affective exploration of this non-actual environment ("vicarious experience" after all, but perhaps of a slightly different kind than Hartvigsen means).

16 For a state-of-the-art overview of the science of $4 \mathrm{E}$ cognition (across multiple domains), see A. Newen, L.D. Bruin, S. Gallagher, The Oxford Handbook of $4 E$ Cognition (Oxford: Oxford University Press, 2018). Useful points of entry for the application to literature are two special journal issues: K. Kukkonen and M. Caracciolo (eds.), 2014; Cognitive Literary Study: Second Generation Approaches, special issue of Poetics Today 48 (2014); B. Morgan, S. Park, and E. Spolsky (eds.), Situated Cognition and the Study of Culture, special issue of Poetics Today 38 (2017). Additionally: K. Kukkonen, 4 E Cognition and Eighteenth-century Fiction: How the Novel Found its Feet (New York: Oxford University Press, 2019). M. Caracciolo, The Experientiality of Narrative: An Enactivist Approach (Berlin: De Gruyter, 2014), 16-23. . These offer something of a history of the field. Such a history is also reflected in (substantial parts of) T. Cave, Thinking With Literature: Towards a Cognitive Criticism (Oxford: Oxford University Press, 2016). Particularly relevant to characterization are e.g. M. Caracciolo, Strange Narrators in Contemporary Fiction: Explorations in Readers' Engagement with Characters (Lincoln: University of Nebraska Press, 2016); M. Polvinen and H. Sklar, "Mimetic and Synthetic Views of Characters: How Readers Process 'People' in Fiction," Cogent Arts \& Humanities 6 (2019): 168-257.

17 P.C. Hogan, Affective Narratology: The Emotional Structure of Stories (Lincoln: University of Nebraska Press, 2011). See p. 40 for his full definition of an "emotion event". 
My point is very much not that such readings are preferable to Hartvigsen's, nor that her paper, that of Kraus, or any of the other contributions in this volume, is somehow "behind the curve."18 And it is worth noting that 4EA cognition, for all of the hype, is not uncontroversial, least of all in the cognitive sciences themselves. As Ralf Schneider points out in this volume, ${ }^{19}$ moreover, there is a risk — not an unavoidable one, to my mind, but nevertheless realthat criticism based on these newer approaches will unduly privilege interpretations of reader engagement as fully absorbed or immersed in storyworlds, as opposed to more distant modalities of response. My own chosen example from Luke is, not coincidentally, particularly amenable to such an immersion-based reading, but it is perhaps a significant observation that the Lukan narrative does not consistently, or even often, lend itself to such readings (and that I struggled to find any comparable passages in the Acts of Peter treated by Kraus).

The previous paragraph began with an assertion of what was not my point: so what is my point in bringing up 4EA approaches? It is (I think) that we can, depending on which branch or version of the cognitive sciences we borrow from, end up with quite different views of how readers engage with characters; and that as long as we are not clear about how well our scientific source material fits together (or doesn't), we will have little basis to decide how views and models deriving from it do. Questions of compatibility, moreover, are real: the originators of discourse comprehension models now deal in embodied versions of such models, but maintaining the edifice requires complicated arguments, and many once seemingly basic facts are now deeply contested. ${ }^{20}$ At their most radical (literally: a relevant book title here is Radicalizing Enactivism), ${ }^{21} 4 \mathrm{EA}$

18 It is, however, interesting to observe disciplinary differences here. My own field of classics seems (somewhat to my own frustration) simply to have skipped "older" (i.e. pre-4EA) but in some ways more useful cognitive approaches to characterization altogether, so it is refreshing to come to a collection of papers which positions itself squarely in that vein of work. Another surprising difference between the framing of this special issue and other cognitive work on characterization with which I am familiar is the rather minimal engagement with Theory of Mind or mindreading (cf. e.g. L. Zunshine, Why We Read Fiction: Theory of Mind and the Novel (Columbus: Ohio State University Press, 2006); B. Vermeule, Why Do We Care About Literary Characters? (Baltimore: Johns Hopkins University Press, 2010); T. Chesters, "Social Cognition: A Literary Perspective," Paragraph 37 (2014): 62-78), something of an obsession of the broader field (to my mind a somewhat misguided one: $\mathrm{cf}$. van Emde Boas, "Mindreading").

19 R. Schneider, "Potential," pp. 542-547.

20 Cf. e.g. Zwaan, "Situation Models."

21 D.D. Hutto and E. Myin, Radicalizing Enactivism: Basic Minds Without Content (Cambridge, MA: MIT Press, 2013). 
approaches would, I think, deny that such a thing as "mental models" can exist (radical enactivism does not buy into the notion of mental representations at all).

One final thought on cognition and affect: a key aspect of cognition implicated here is memory. The whole discourse processing model hinges, of course, on memory: as Hartvigsen summarizes, ${ }^{22}$

The construction of a ... coherent ... mental representation of a particular character is ... a dynamic process that takes place in working memory .... During this process, readers and listeners continually update the mental character model by integrating incoming textual data with their personal knowledge structures that are brought out of long-term memory.

As I hinted above, this is, on the surface at least, a rather affect-free view of how memory works. It is a well-established phenomenon, however (somewhat irrespective of 4EA-developments), that memory and emotion are deeply intertwined: "emotions profoundly influence how we encode information,"23 not only by colouring our memories, but by determining which information we encode as memories in the first place. If we return to our moment from Luke and also bring in the later appearance of the angel Gabriel to another character, Mary (Luke 1:28-29),

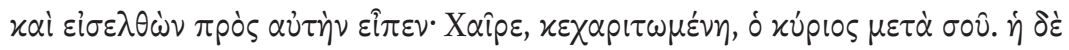

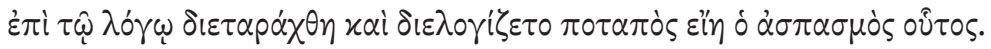

And he came to her and said, "Greetings favored one! The Lord is with you." But she was much perplexed by his words and pondered what sort of greeting this might be.

and if we then consider, with Hartvigsen, ${ }^{24}$ that the reader's response to the latter moment will likely be influenced by the memory of the former, it is surely relevant that the memory so triggered is bound up with emotions, presumably both those of the character and those of the reader.

\footnotetext{
22 K.M. Hartvigsen, "Audience," p. $55^{8}$.

23 A.-K. Stock, H. Gajsar, and O. Güntürkun, "The Neuroscience of Memory," in K. Galinsky (ed.) Memory in Ancient Rome and Early Christianity (Oxford: Oxford UP, 2016), 369-371 (379).

24 K.M. Hartvigsen, "Audience," p. 576.
} 


\section{Meaning}

Here is the end of Acts of Peter 11:

Et sparsit super lapides aquam, et statua integra facta est. Petro itaque gloriante quod non dubitasset in petendo dominum, sed et Marcellus in spiritu exaltabatur, quod tale signum primum inter manus eius factum fuisset. Credens ergo ex totis praecordiis suis in nomine Iesu Christi filii dei, per quem omnia inpossibilia possibilia sunt.

And he sprinkled water on the stones, and the statue became whole. Peter was proud therefore, that he hesitated not to petition the Lord; but Marcellus also rejoiced in the Spirit, that such a sign - the first onetook place under his hands. He believed therefore with all his heart on the name of Jesus Christ, the Son of God, by whom all things impossible become possible. ${ }^{25}$

We learn quite a bit about Marcellus from the passage describing his miracle, as Kraus's analysis demonstrates. ${ }^{26}$ For Kraus, in the "assemblage of character features" 27 that make up a reader's mental model of Marcellus, this passage marks (at least) his behaviour, his supposed knowledge (of earlier miracles), his motivation(s), and the way that he is embedded in a significant space (his house). I think we could easily extend the analysis towards even further members of Kraus's list of character features, for instance to Marcellus' feelings (exaltabatur, "he rejoiced"), perception (he witnesses a sign), and possibly things like standpoint. But even if we exhaust every item on Kraus's list, I wonder if we will have reached a fully satisfying analysis of this moment and what it tells us about Marcellus' literary character. Indeed, Kraus's accompanying footnote (n. 62) suggests, following Döhler, that there is much more to make of this moment: paraphrasing the footnote, one might say that the restitution miracle symbolizes Marcellus' restoration to the Christian faith, and potentially also represents the political dimension of conflicting Romanness and Christianity.

"Symbolizes," I just wrote, and "represents." For a literary critic these are perhaps not outrageous claims to make: yet how such claims can be properly accounted for by the models under discussion is, I think, not always clear, or

25 Text: M. Döhler, Acta Petri: Text, Übersetzung und Kommentar zu den Actus Vercellenses (Berlin: De Gruyter, 2018). Translation: B. Pick, The Apocryphal Acts of Paul, Peter, John, Andrew and Thomas (Chicago: Open Court, 1909).

26 T.J. Kraus, "Dramatis personae," p. 608.

27 T.J. Kraus, “Dramatis personae," pp. 6o1-6o2. 
at least not explicitly made clear. The point is that in literature, people and their actions can be something different, even "mean" something more, than just people and actions - that is, they can formed by, and formative of, other aspects than their supposed psychological endowments, backstories, and so forth. This, again, is not in any way news: debates about whether literary characters are fundamentally "person-like" or not ("people or words") have raged for a century and more, sometimes with rather violent pendulum swings (not least in my own field). Various theorists have attempted to capture the different constitutive dimensions of literary character in a single integrative model; a particularly elegant and influential example is the tripartite model of James Phelan, ${ }^{28}$ mentioned by Hartvigsen in her footnote 18. Phelan distinguishes between a "mimetic" component (capturing the ways in which characters can be interpreted in ways analogous to actual persons), a "synthetic" component (capturing the ways in which characters are artificial constructs, the product of textual cues, narrative patterns, preconditioned mythical roles, and so forth), and finally a "thematic" component (capturing the ways in which characters can be taken as the embodiment of particular larger themes or ideas, or the expression of a particular world view).

The challenge for cognitive theories of characterization is how to integrate the synthetic and thematic aspects of literary character alongside the mimetic one, as only the latter (the mimetic) is a natural target for some of the scientific models applied, based as they are on the understanding of "real" people (e.g. attribution, Theory of Mind/mindreading, social roles and schemas, etc.). To take another example from Hartvigsen's chapter, we might contrast two of Mary's utterances, one at Luke 1:34, where, confronted with Gabriel,

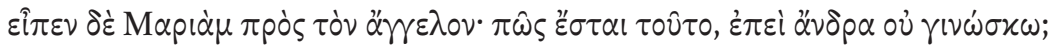
Mary said to the angel, "How can this be, since I am a virgin?"

the other at Luke 1:46-55, at Zechariah and Elizabeth's house, where in her praise of the Lord, she foretells among other things:

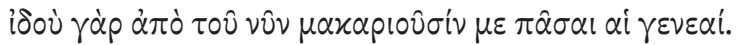

Surely, from now on all generations will call me blessed.

On a purely mimetic analysis we might struggle to explain the remarkable knowledge gap between the Mary of the latter scene (who can fairly confidently

28 J. Phelan, Reading People, Reading Plots: Character, Progression, and the Interpretation of Narrative (Chicago: Chicago University Press, 1989), 2-3. 
predict the future) and the Mary of the former (who does not yet fully understand it). As a solution, we could attempt to adduce Culpeper's distinction, deriving from attribution theory, between internally and externally driven behaviour, and between the different kinds of inferences about character that these different forms of behaviour license. ${ }^{29}$ On such an account Mary's later prophetic utterance cannot be linked to her own character traits, but comes from some external source of inspiration. But I am not convinced that even on such a reading we have a fully satisfying view of who and what Mary is as a biblical character. Indeed, Hartvigsen's analysis of this moment trends in other directions, including an extensive discussion of what Mary's utterances here tell us, both explicitly and implicitly, about God.

That cognitive approaches to character deal less well with the more "literary" aspects of characters is, again, not a new complaint. Such criticisms have come particularly loudly from the corner of "unnatural narratology," whose proponents emphasize, very roughly speaking, that narrative is often not like real life. Thus Brian McHale warns that cognitive narratology (as often currently pursued) lacks an "attentiveness to literary convention," and Maria Mäkelä argues that "by reducing fictional minds to exempla of actual human cognition we miss the essential dynamics between verbal art and real-life experientiality."30 Very recently, from a slightly different angle, Polvinen and Sklar have again taken aim at David Herman's notion that there is no fundamental difference between the cognitive processes involved in making sense of "real" and of literary people (Herman argued against what he calls the "Exceptionality Thesis"). ${ }^{31}$ There is certainly something to these critiques, although I think that the right kind of cognitive model (a carefully eclectic one, as argued above) can solve some of these problems. Indeed, one of the real advantages of the Culpeper/ Schneider-style discourse processing model of characterization-leaving aside all the questions of compatibility and the scientific background raised above-is that it makes ample room for literary convention and artificiality,

29 K.M. Hartvigsen, “Audience," p. $55^{8}$.

30 B. McHale, "Transparent Minds Revisited," Narrative 20 (2012): 115-124 (123); M. Mäkelä, "Cycles of Narrative Necessity: Suspect Tellers and the Textuality of Fictional Minds," in L. Bernaerts, D. De Geest, L. Herman, and B. Vervaeck (eds.), Stories and Minds: Cognitive Approaches to Literary Narrative (Lincoln: University of Nebraska Press, 2013), 129-151 (130). Cf. also Kukkonen, $4 E$ Cognition, ch. 1.

31 Polvinen and Sklar, "Mimetic." D. Herman, "Introduction," in D. Herman (ed.), The Emergence of Mind: Representations of Consciousness in Narrative Discourse in English (Lincoln: University of Nebraska Press, 2011), 1-40 is the fullest formulation of his argument against the Exceptionality Thesis ("the claim that readers' experiences of fictional minds are different in kind from their experiences of the minds they encounter outside the domain of narrative fiction," p. 9). I discuss these issues further in van Emde Boas, "Mindreading." 
by including literary schemas as those which a mental character model may activate (see Hartvigsen, pp. 558-559). Still, I think, the "words-versus-people" problem cannot be gotten rid of so easily, and it is notable that even in our bold new cognitive era of criticism, we seem to be going through some of the same swings and movements (those which Culpeper called "humanizing" and "dehumanizing") ${ }^{32}$ as other forms of literary criticism have done before us. ${ }^{33}$ In the end, this tension is likely to remain, as it derives from a fundamental aspect of literature, namely that it is (in various degrees) simultaneously like and unlike life.

\section{Conclusion}

It will be clear that much of this response has been concerned with broader directions in cognitive literary studies (on characterization but also more broadly), as much as it has with the particular contributions of Hartvigsen and Kraus (both of which, I will emphasize again, I found very convincing). One potential emerging conclusion is that, for the cognitive literary studies enterprise as a whole, it is vital that we engage seriously and critically with the scientific disciplines with which our fields now interact. There are real risks of mixing incompatible models, misinterpreting scientific data or theories, all-too-quickly turning controversial scientific theories into explanations of everything (see: mirror neurons; perhaps also blending), and so forth. But all these caveats (which I am in no way the first to express) presuppose only one direction of travel, from the "harder" sciences to the "softer" humanities: that, however, is not the only direction we should be travelling. ${ }^{34}$ There are not infrequent claims in the cognitive humanities of bi-directionality, of "giving back" to the cognitive sciences. ${ }^{35}$ To give a bit more of the "view from classics" that I promised in my introduction: there have been some fledgling but energetic explorations of how classicists can not only draw on psychology, neuroscience, or cognitive linguistics to better make sense of our own texts and

\footnotetext{
32 Culpeper, Language, 6-9.

33 On the tendency for character criticism to recycle similar questions within different frameworks, cf. already Pelling, "Conclusion," 254, "We can easily find ourselves rephrasing the conventional questions in ... slightly different terms."

34 My argument in the remainder of this paragraph is strongly influenced by Budelmann, "Introduction."

35 A recent book which is explicitly framed around such bi-directionality is M. Burke and E.T. Troscianko (eds.), Cognitive Literary Science: Dialogues between Literature and Cognition (New York: Oxford University Press, 2017).
} 
materials, but also ourselves tackle questions of cognition through the study of literature, partly but not exclusively through actual interdisciplinary (including empirical) research. One reason why classicists can and should play such a role is that we curate, as it were, an "archive" (Terence Cave's term) ${ }^{36}$ of highly significant products of human cognition (namely the art, literature, etc., of antiquity) - a body of material that does not immediately present itself to the cognitive scientist as the most obvious object of study, but that should nevertheless very much be part of a full account of what human cognition is capable of. This argument, I would suggest by way of conclusion, is extremely relevant as well (mutatis mutandis) to New Testament scholars: they, too, are uniquely positioned to use their own (incredibly important) material, and their own methods, to think through fundamental questions of cognition, including how we make sense of other people-whether those we meet in our everyday lives, or those we meet in the bible.

36 Cave, Thinking. 